\title{
Capturing the worlds of multiple sclerosis: Hannah Laycock's photography
}

\author{
Stella Bolaki
}

\section{Correspondence to} Dr Stella Bolaki, School of English, University of Kent, Rutherford College Extension, The Spires, Canterbury, Kent CT2 7NX, UK;

S.Bolaki@kent.ac.uk

Accepted 9 October 2016

Published Online First

31 October 2016
CrossMark

To cite: Bolaki S. Med Humanit 2017;43:47-54.

\section{ABSTRACT}

This essay explores UK photographer Hannah Laycock's Awakenings and, to a lesser extent, Perceiving Identity that were created in 2015, following her diagnosis with multiple sclerosis (MS) in 2013. It draws on scholarship by people with chronic illness while situating these two MS projects in the context of Laycock's earlier art and portrait photography dealing with fragility, image and desire, and power relations between subject and observer. The analysis illustrates how her evocative photography captures the lived or subjective experience of an invisible and often misunderstood condition by initially focusing on the tension between transparency and opacity in her work. It further shows how her images counter dominant didactic metaphors such as, 'the body as machine', that perpetuate the dehumanising and objectifying aspects of medical care. Subsequent sections trace the influence that Oliver Sacks has had on Laycock's practice, and reflect on other metaphors and tropes in Awakenings that illuminate the relationship between body and self in MS. The essay concludes by acknowledging the therapeutic power of art and calling upon health professionals to make more use of such artistic work in clinical practice.

\section{INTRODUCTION: MULTIPLE SCLEROSIS, NARRATIVE AND PHOTOGRAPHY}

Following her diagnosis with multiple sclerosis (MS) in 2013, Hannah Laycock's photography turned to an exploration of the feelings associated with this experience in her projects Perceiving Identity and Awakenings created in 2015: the former, consisting of 12 images, was launched in London; and the latter, consisting of 16 images, in Glasgow. This is not the first time Laycock explores illness as Railing at the Enthrallment to the Failing of the Light (Parts I-II, 2009) had documented 'the emotional terrain of her parents' life' following her father's diagnosis with motor neuron disease. ${ }^{1} \mathrm{Her}$ subtle, contemplative and sensuous work on MS contributes to contemporary photography, particularly art and portrait photography, and to illness narratives that come in various forms in contemporary culture: from memoirs, performance art, film and conversations in a clinical setting to graphic novels, online blogs and social media posts. ${ }^{2}$ Rather than providing a list of symptoms and diagnoses, illness narratives offer a deeper understanding of the experiences and feelings that are part of the process of being ill and can therefore inform clinical practice by increasing empathy. They can raise awareness about particular conditions and can also function therapeutically and politically-in allowing people to find voice and meaning in the shaping of their stories, as well as to regain ownership of their bodies from the often depersonalising experience of being a patient.

A common misunderstanding about MS, a lifelong condition which can affect the brain and/or spinal cord, causing a wide range of potential symptoms, is that everyone who has been diagnosed with it will eventually need to use a wheelchair or that, if they do not, their situation must be somehow easier to manage. Laycock has noted how many people say to her 'Oh, but you look really well' and explains 'All the symptoms I'm actually dealing with you're not going to see, because they're all beneath the surface.' ${ }^{3}$ No two people with MS have the same experience, and symptoms that may include fatigue, vision problems, numbness, pain and cognitive difficulties can change daily creating uncertainty. American author Nancy Mairs has described her experience of living with this condition as being 'haunted by a capricious and meanspirited ghost, unseen except for its footprints, which trips you even when you're watching where you're going ... and weights your whole body with a weariness no amount of rest can relieve' (pp 83-4 in Mairs ${ }^{4}$ ). Many patients with MS resort to metaphors and analogies to describe how they feel, and their accounts show the difficulty of reconciling medical classifications of bodily symptoms with the way they are perceived by individuals. ${ }^{\mathrm{i}}$ The nature of MS, as is the case with physical pain, ${ }^{5}$ other 'hidden' chronic conditions and mental ill health that are difficult to describe or visualise, poses challenges for medicine and for narrative and photography. This difficulty is highlighted if we consider, for example, a turning point in British photographer Jo Spence's projects of documenting illness: the visual language she had found for breast cancer in her raw images of the scar did not seem 'applicable' after she was diagnosed with leukaemia, a condition that was 'almost impossible to represent' (p. 215 in Spence ${ }^{6}$ ). Such invisibility often leads to a lack of social support and sympathy, which is an additional obstacle for the patient.

Laycock's practice may initially raise the question what one can show or say about MS through photography 'that is not said more directly or more clearly from a medical, scientific or documentary perspective' (p. 38 in Radley ${ }^{7}$ ). A photograph 'is supposed not to evoke but to show', which is why 'unlike handmade images, photographs can count as evidence' (p. 42 in Sontag ${ }^{8}$ ). Perceiving Identity

${ }^{\mathrm{i}} \mathrm{See}$, for example, descriptions by online MS communities (Positive living with MS, http://positivelivingwithms.com/ 2016/03/01/what-ms-really-feels-like/ (accessed 30 July 2016); The mighty, https://themighty.com/2016/01/ what-it-feels-like-to-have-multiple-sclerosis/ (accessed 30 July 2016).). 
and Awakenings are not documentary photography, and do not deal with medical content (eg, brain scans) or symptoms directly. The photographs are untitled and do not seem to have any temporal order; in exhibition spaces, they are scattered, sometimes suspended, rather than arranged in a linear way. Even though the artist's statements place them in a kind of narrative and they are 'traversed by language' when they are interpreted by viewers (p. 144 in Burgin ${ }^{9}$ ), there is not a fixed story being told or narrative closure. Closer to the expressive and affective language of painting-Laycock defines photography as 'painting with light ${ }^{\text {ii }}$ - they have an evocative power: they communicate through texture, light, psychedelic self-portraiture and metaphors the lived or subjective experience of the body and of chronic illness.

Drawing on scholarship by people diagnosed with chronic illness, the following analysis illustrates how Laycock's evocative photography captures what it feels like to live with an invisible and often misunderstood condition. The first section addresses the tension between transparency and opacity in her MS projects and its potential to produce alternative visualisations of the body that counter the dehumanising and objectifying aspects of medical care. Subsequent sections trace the influence that Oliver Sacks has had on Laycock's practice and reflect on other metaphors and tropes in her work that illuminate the relationship between body and self in MS. The essay concludes by acknowledging the therapeutic power of art and calling upon health professionals to make more use of non-medical photography in their practice. Throughout my analysis, I situate Laycock's MS photography in the context of her earlier art and portrait photography dealing with fragility, image and desire, and power relations between the subject and observer. While I discuss images from her first project on MS, Perceiving Identity, I have chosen to focus more extensively on Awakenings as it develops many of the earlier themes and relates more explicitly to the aims of this essay.

\section{THE LIVED BODY: TRANSPARENCY AND OPACITY}

Even though the sensations and emotions Laycock's photography evokes will differ from viewer to viewer, there is a feeling 'of confusion and submersion-as if the entire world was being viewed from behind a diluted bottle of milk'. ${ }^{3}$ One of the images from Perceiving Identity is a portrait of the artist in the woods, her face obscured by fog (figure 1); another of her in a bath. Laycock notes that there is a 'haziness to the water' she is submerged in and adds that it represents the 'cognitive issues you get and the memory problems. It's a fogginess, a fatigue'. ${ }^{3}$ Other photos of this project are equally blurry, concentrate on the play between shadow and light or focus on small objects like a seashell or a butterfly, forcing viewers to get close to them. The impression they give is that of the artist attempting to perceive the world and individual identity afresh. Laycock's statement seems to support this interpretation as it refers to a 'dreamlike state; pulsating in and out of consciousness grasping onto the minutiae in the hope for clarity in the pronouncement and acceptance of her Multiple Sclerosis diagnosis'. ${ }^{10}$

In addition to visualising symptoms that are typical of $\mathrm{MS}$, ${ }^{\mathrm{iii}} \mathrm{I}$ would suggest that such photographs serve as a broader

\footnotetext{
${ }^{\text {ii }}$ Six foot gallery. Hannah Laycock: artist in residence, https:/ sixfootgallery.com/2015/08/06/hannah-laycock-artist-in-residence/ (accessed 30 July 2016).

iiiThis is the main aim of the photography project 'Seeing MS' (Seeing MS: exposing the invisible disease, http://www.seeingms.com.au/ (accessed 30 July 2016).).
}

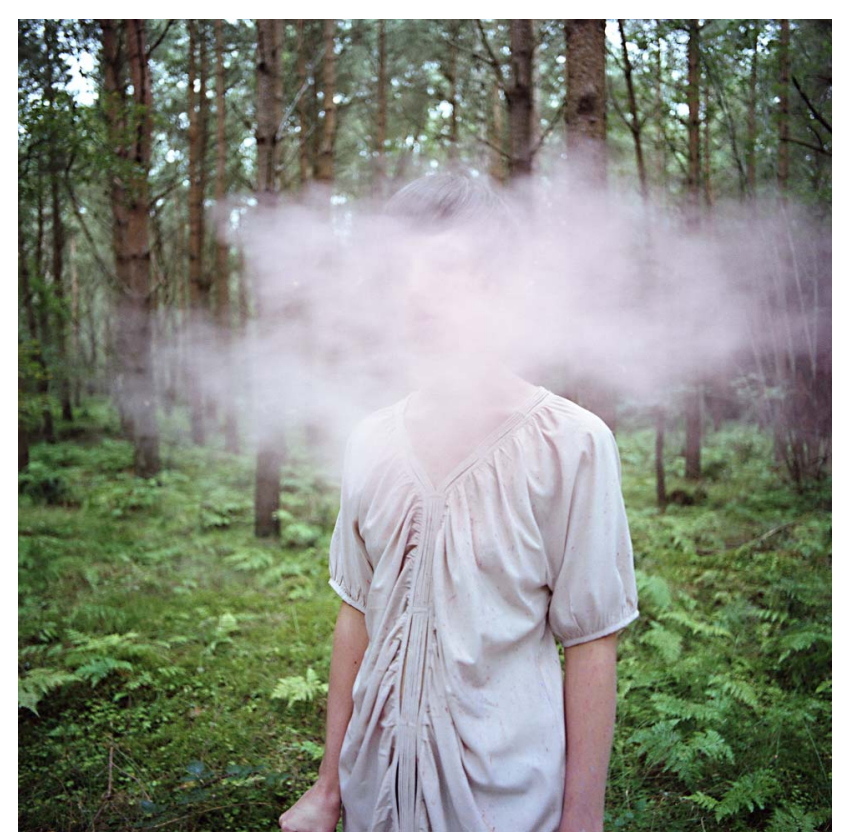

Figure 1 Hannah Laycock, Untitled, Perceiving Identity, 2015.

metaphor for living with illness. Writing from the perspective of experiencing chronic illness, Havi Carel explains that it is only when something goes wrong with the body that it becomes the focus of our attention and thus stops being 'an invisible background' that allows other activities (such as routine, everyday activities) to take place: 'Illness is an abrupt, violent way of revealing the intimately bodily nature of our being' (p. 26 in Care ${ }^{11}$ ). This also applies to cognition; certain disorders may interrupt processes like learning and remembering that frequently occur without conscious awareness. Fredrik Svenaeus describes being ill as finding 'oneself in a pattern of disorientedness, resistance, helplessness and perhaps even despair, instead of in the homelike transparency of healthy life' (p. 103 in Svenaeus, ${ }^{12}$ emphasis added). Many photographers use blurriness and grain to obscure, even as they expose, their subjects, and Laycock herself has experimented with projects that particularly obscure the face creating a 'sense of unease and bewilderment' for the viewer (eg, in Portraiture and the Gaze ${ }^{13}$ ). Through similar techniques such as fogginess and blurriness in Perceiving Identity that are further developed in Awakenings, Laycock captures the vision and cognitive difficulties associated with MS. She also sheds light on the disruption to the harmony between the biological (the physical or material body) and the 'lived body' (the first-person experience of the biological body) that takes place with illness more generally; in other words, her work catches a glimpse of the moment when the body, losing its 'healthy transparency', becomes opaque.

Transparency, however, is a powerful metaphor in medicine too, as the medical gaze is deemed to make the body 'transparent' through physical examination, dissection and sophisticated imaging techniques (A Bleakley. Thinking with metaphors in medicine: re-shaping clinical work. London: Routledge, forthcoming, http://www.medicalmetaphors.com/ (accessed $30 \mathrm{Jul}$ 2016).). ${ }^{14}$ Disability and performance studies scholar Petra Kuppers suggests that works by visual and performance artists that explore illness by setting up a tension between transparency and opacity destabilise dominant knowledge systems such as Western medicine by undoing 'some of the certainties, some of the labeling and identifications that are the currency of medical 
diagnosis' (p. 3 in Kuppers ${ }^{15}$ ). Rather than offering 'an authoritative map to someone's bodily experience' (through MRIs, scientific graphs and diagrams that circulate in various MS websites) Laycock joins other artists who make the ill person 'visible and experiential without making [him or her] fully knowable' (pp. 53, 2 in Kuppers ${ }^{15}$ ). This is a way of exploring, and sometimes embracing, uncertainty and ambiguity which medicine and science are largely resistant to: ${ }^{2} 15$ 'the undecidability of opacity or unclear vision can set up a desire to know, a journey toward that which isn't fully given to be known' (p. 47 in Kuppers ${ }^{15}$ ).

Laycock's photography documents her own unpredictable MS journey while also establishing a connection with her audience. The images with the fog and the hazy bath water draw us closer precisely because of their lack of clarity, which goes against the expectation that photography represents reality as truthfully as possible. But, at the same time, they resist the fantasy of full identification: we cannot see the full picture; we can get close to these experiences but not own them, and thus are encouraged to inhabit a space between self and other that keeps open the possibility of (re)encountering and witnessing difference. Laycock has used her photography to explore the power relations between the subject and the observer in Portraiture and the Gaze as well as in Primacy Subject, where the subject in every image holds a mirror that prevents the observer from seeing their face, reflecting instead the scene around the subject. Similarly, her photographic projects on MS imagine, and generate knowledge about, the body in ways that become experiential for both the artist and her viewers without presupposing that those who receive that experience can know what exactly it is like.

Laycock's evocative and non-totalising work produces 'thicker' accounts of health and illness through the tension between transparency and opacity and by opening up the idea of the body as traditionally understood and visualised by medicine. Dominant didactic metaphors in medical education, such as 'the body as machine', perpetuate the dehumanising and objectifying aspects of medical care. 'The brain is like a jumble of wires. MS strips them of their insulation' (A Bleakley, forthcoming) is an example that subscribes to such dominant metaphors, but says nothing about the ways in which MS affects the relationship between body (in this case, the brain) and one's sense of self. As S Kay Toombs, who is also living with MS, writes, illness is experienced by the patient

more fundamentally as a disintegration of his 'world' ... Lived body (my embodiment) is not extrinsic to the self. In fundamental ways I AM my body. A threat to the body necessarily incorporates a threat to my very self; ... Consequently, illness results not only in a disintegration of body but in a disintegration of self and world. (p. 207 in Toombs ${ }^{16}$ )

Oliver Sacks, who unsurprisingly has an influence on Laycock's work, has expressed the same idea: in illness, 'a world is lost or broken or unmade, reduced to bits and pieces, to chaos-and it is a world, no less, that must be remade' (p. 18 in Sacks ${ }^{17}$ ). Artistic visualisations of the body can therefore be beneficial to both patients and the medical community: they can lessen patients' alienation (often exacerbated by impersonal medical imaging technology) and pave the way for new educational metaphors within medical culture by encouraging varied interpretations of the body and an expression of the multiple worlds of illness.

\section{OLIVER SACKS' INFLUENCE ON LAYCOCK'S PRACTICE}

The artist's statement accompanying Perceiving Identity opens with a passage from the introduction of Sacks' famous book of clinical tales, The Man Who Mistook His Wife for a Hat, about 'neurology's favourite word' which is 'deficit'. The word denotes 'an impairment or incapacity of neurological function: loss of speech, loss of language, loss of memory, loss of vision, loss of dexterity, loss of identity and myriad other lacks and losses of specific functions (or faculties)'. Following that, the project is described as 'a photographic journey' that explores 'feelings of uncertainty, fear, loss and liberation, intuitively delving into and questioning the notion of this neurological "lack". ${ }^{10}$ Perceiving Identity was made in response to the \#GOOB brief (GOOD OUT OF BAD) commissioned by the charity Shift.ms. Photography after all which creates a 'positive' out of a 'negative' image is an apt tool when it comes to subverting disempowering metaphors about illness. Laycock further quotes the following lines from Sacks' tale 'The Lost Mariner': "'How do you feel?" "How do I feel?" He repeated, and scratched his head. "I cannot say I feel ill. But I cannot say I feel well. I cannot say I feel anything at all"' ${ }^{10}$ Drawing attention to the limitations of language here, the artist's challenge is to use her camera as an alternative means of capturing the liminal sense of being neither ill nor well.

Laycock's debt to Sacks is also evident in her choice of the title Awakenings for her next photographic project. In his study of the same title, Sacks challenged the conventional medical case history after working with patients with encephalitis lethargica at Mount Carmel Hospital in New York in the late 1960s and early 1970s. Bemoaning the objective and technical style of neurology, he wrote that 'nowhere does one find any colour, reality, or warmth: nowhere any residue of the living experience; nowhere any impression or picture of what it feels like to have Parkinsonism' ( pp 230-1 in Sacks ${ }^{18}$ ). Sacks' tales follow patients' responses to L-DOPA, the new 'awakening' drug that brought them out of the 'sleeping sickness epidemic' that swept the world just after World War I. Rather than merely listing symptoms and offering quantitative data, his stories are full of 'images and metaphors'. Justifying such narrative choices, Sacks writes, 'My aim is not to make a system, or to see patients as systems, but to picture a world, a variety of worlds-the landscapes of being in which these patients reside'. Awakenings therefore is the result of his attempt to bring together 'an objective description of disorders, mechanisms, syndromes', with a 'more existential and personal-an empathic entering into patients' experiences and worlds' (pp. xviii, xxxvi in Sacks ${ }^{18}$ ).

Laycock has acknowledged the power of Sacks' writing to conjure visual images that can be developed into actual photographs to provide what is missing from representations of MS, whether scientific or lay ones (Skype interview with author, 22 May 2016). Sacks writes of his own feelings 'of amazement and wonder, and almost of awe' when he saw the effects of L-DOPA on his patients:

This sense of worlds upon worlds, of a landscape continually extending, reaching beyond my sight or imagination, is one which has always been with me, ... It is a very mixed landscape, partly familiar, partly uncanny, with sunlit uplands, bottomless chasms, volcanoes, geysers, meadows, marshes; ... archaic, prehuman, almost prehistoric, with a sense of vast forces simmering all round one. (p. 231 in Sacks ${ }^{18}$ )

Laycock's landscape images are often set in her native Scotland where she returned after experiencing a relapse in July 2015. She has described the forest and the sea in the Highlands 
as 'a place I see as having a magical spirit and landscape', and the statement that accompanies Awakenings refers to 'the rough shapes and features of the rocks and the rivers' as transmitting 'an impression of enduring persistence and strength'. ${ }^{19}$ Here, the (female) body that is visible in some of the self-portraits is metaphorically transposed into a landscape, solid and liquid, conveying change and movement as well as stillness and endurance. Through such contrasts and the play between shadow and light, these photographs capture the evolving and changing landscape of the MS condition and the artist's open-ended journey through it (figure 2).

Her use of colour could be equally seen as a response to Sacks' earlier plea for some 'colour, reality, or warmth, a residue of the living experience'; adding colour does not necessarily beautify or idealise as exemplified in an image of the artist's head covered with fabric that illustrates suffocation (figure 3). Laycock notes: 'My breathing is no longer automatic. I have to think about each breath, and every so often I am forced to gasp'. ${ }^{19}$ However, it is also a colourful picture (both the fabric and the background against which her body is photographed are in different shades of blue)-'there is hope and light at the end of the tunnel'. ${ }^{3}$ The same could be said of the psychedelic portraits of the artist's skin melting or disintegrating that are discussed later; the images are visually striking in their choice of colours despite the visceral quality of their subject matter.

Awakening has literal and figurative meanings, signifying both an emergence from sickness and a spiritual kind of rebirth in both Sacks' and Laycock's works. Sacks describes the awakened patient as someone who 'turns an eager and ardent attention on the world', 'the stream of being, no longer clogged or congealed, flows with an effortless, unforced ease' (p. 241 in Sacks ${ }^{18}$ ). Countering the common metaphor of the diseased body as a battlefield, ${ }^{20}$ many of Laycock's images evoke a sense of communion with nature, where the artist's body and the surrounding landscape blend seamlessly (figure 4), as well as 'the sense of spaciousness' associated with awakening (p. 241 in Sacks ${ }^{18}$ ). They are introspective and quiet, yet at the same time strong, as she adds, 'perceiving that Nature is resilient and comforting to me'. ${ }^{19}$ Awakenings also includes photographs that exploit the tension between limitation and expansion such as the juxtaposition of a brick wall against a mirror reflecting a blue sky with white clouds (recalling a similar use of mirrors in Primacy Subject). This layered image (figure 5) presents us with two axes: a 'horizontal' one (the wall) that conveys containment and stagnation; and a 'vertical' one (the sky in the mirror) that conveys elevation and escape or transcendence of the body. These photographs reveal something important about the mode of living with MS which is so often about balancing the body, balancing health and illness and balancing body and mind-the celestial contrasting with what brings down to earth. As Mairs writes, the most difficult aspect of adjusting to MS is 'the fact that it has rammed my "self" straight back into the body I had been trained to believe it could, though high-minded acts and aspirations, rise above' (p. 84 in Mairs ${ }^{4}$ ).

Such alternative ways of visualising the body in Awakenings are not self-indulgent fantasies given that they come from the person herself who experiences MS. Rather than aestheticising a condition that is often 'invisible' and debilitating, they generate rich associations and images that challenge mechanistic conceptions of the body in medicine, just as Sacks does with his accounts of his patients in his writings. It is in doing such 'work' that aesthetic practice can be seen as counteracting the kind of 'deficit' or 'loss' associated with disability and offering a sense of agency and freedom to people who are ill. Mairs expresses this idea succinctly when she notes-on the topic of
Figure 2 Hannah Laycock, Untitled, Awakenings, July 2015, Scotland.

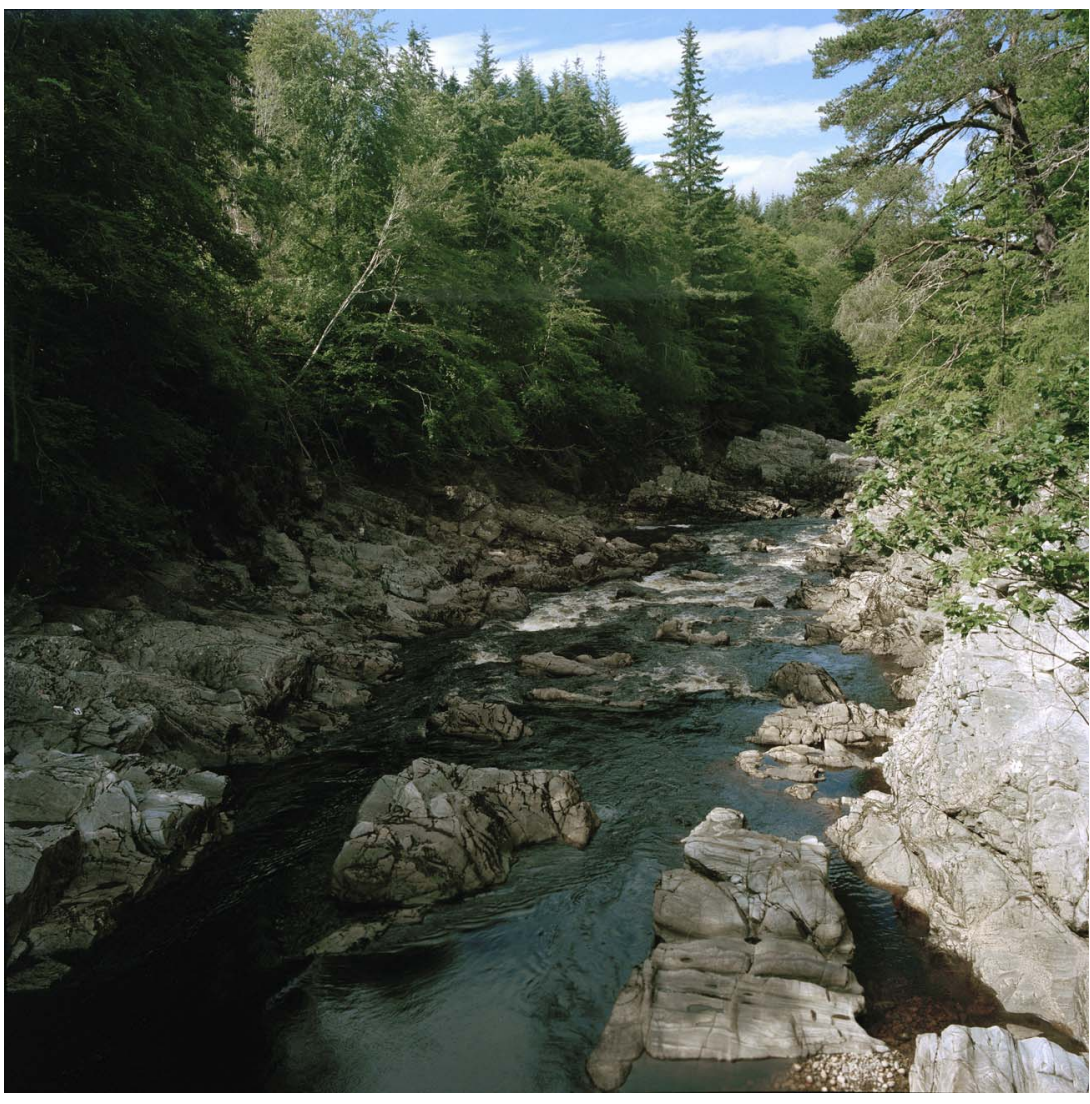

Bolaki S. Med Humanit 2017;43:47-54. doi:10.1136/medhum-2016-011073 


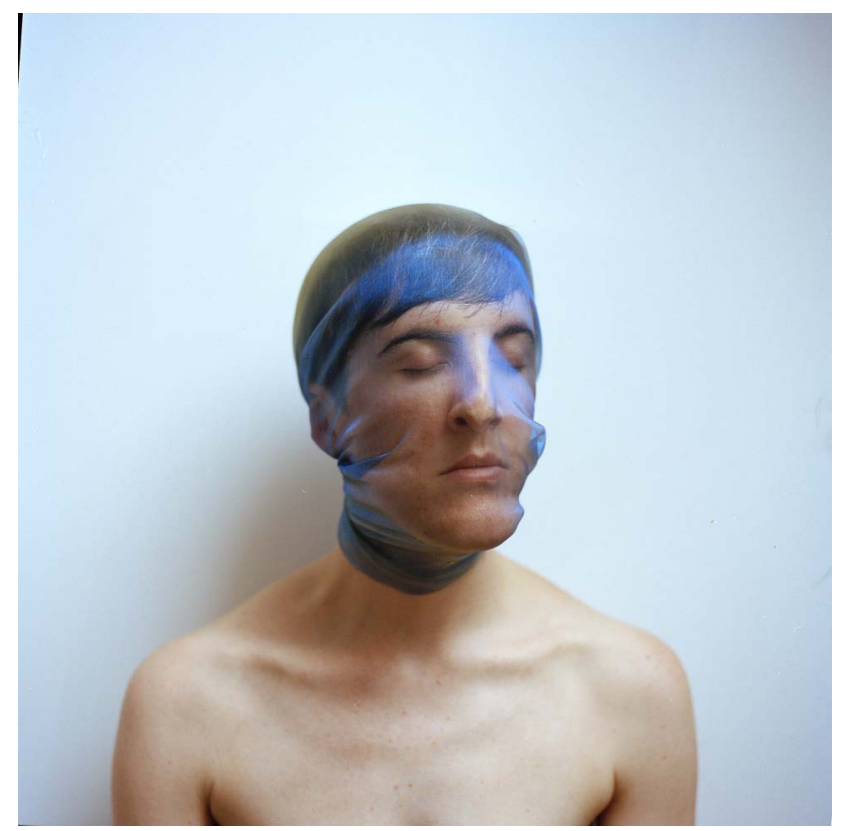

Figure 3 Hannah Laycock, Untitled, Awakenings, July 2015, Scotland.

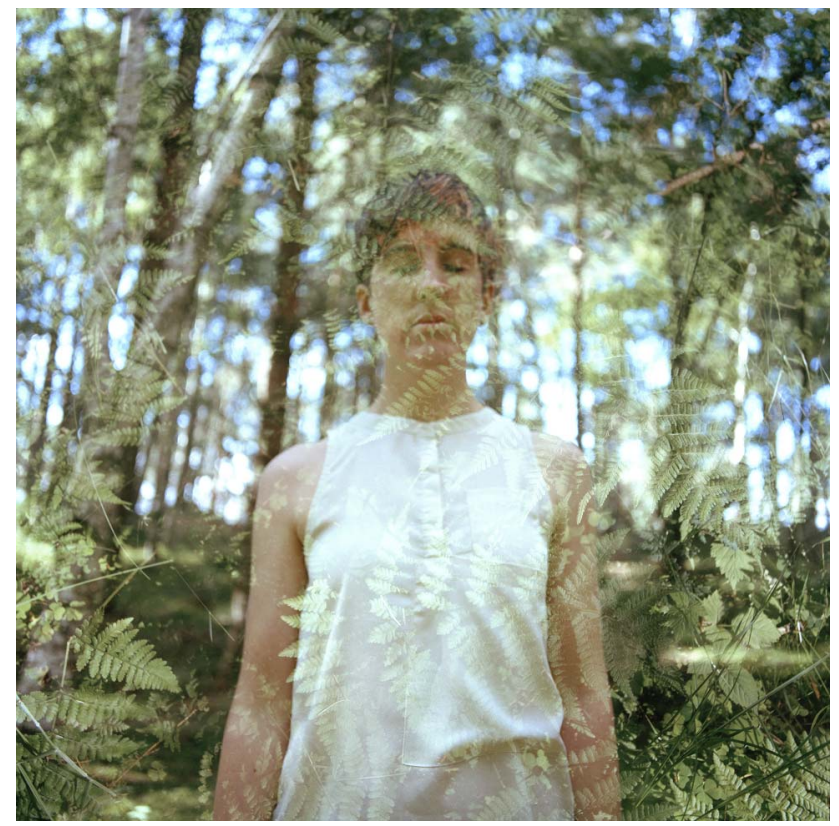

Figure 4 Hannah Laycock, Untitled, Awakenings, July 2015, Scotland.

finding a new voice in her writing after her diagnosis-'paradoxically losing one sort of nerve has given me another'. It is a voice that 'wants to crack, to whisper, to trail back into silence' but which she holds on to nevertheless in order to redeem both "cripple" and "woman" from the shameful silences by which [she has] often felt surrounded' (p. 96 in Mairs ${ }^{4}$ ).

\section{BODY AND SELF IN MS}

A 'healthy' body knows where different body parts are through a 'body image' in which 'all are included' and does not have to 'behold as a spectator' their relations (p. 206 in Toombs ${ }^{16}$ ). A sense of alienation from one's body - the body as uncanny (both familiar and unfamiliar)-is captured in many of Laycock's

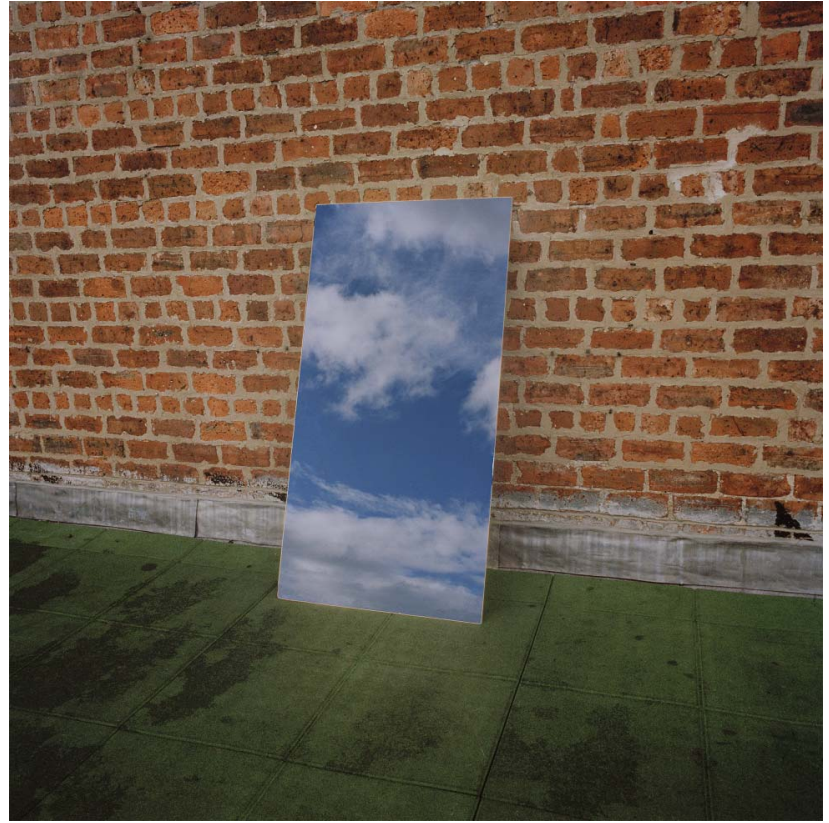

Figure 5 Hannah Laycock, Untitled, Awakenings, July 2015, Scotland.

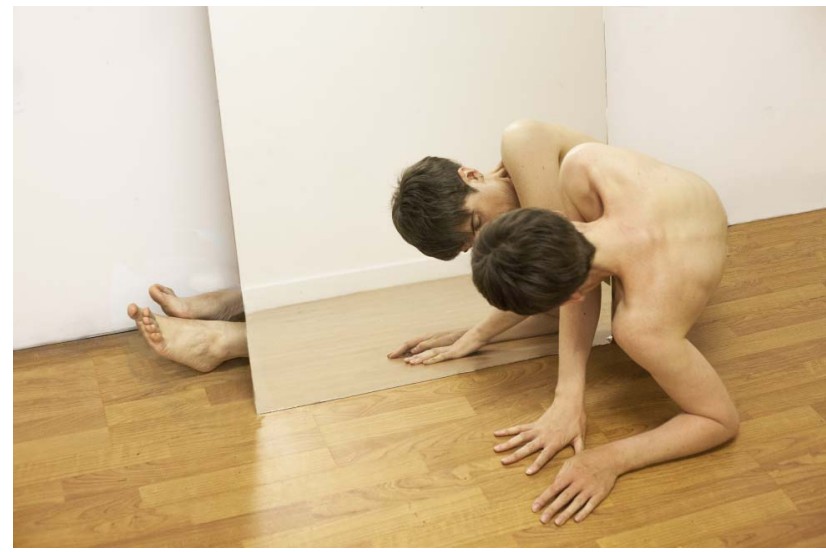

Figure 6 Hannah Laycock, Untitled, Awakenings, July 2015, Scotland.

photographs through the trope of the mirror. In one image from Awakenings, the artist is on the floor, naked in front of a mirror (figure 6). As in American photographer Francesca Woodman's picture (Untitled, 1975-1980) of a dark tall door cutting her body that is underneath into two halves, the mirror bisects Laycock's body and makes it appear chopped up at first glance. Viewers are aware of both the realness and unrealness of the person mirrored; her body, like that of a puppet, appears human and inhuman simultaneously, more dense as it gets amplified through the mirror, and yet fragmented and disconnected as it is not reflected as unified or whole. Laycock has explained that one of her MS symptoms is numbness in the lower half of her body, and this image where the feet are presented as if they do not belong to the rest of the body could be seen as signifying that (Skype interview with author, 22 May 2016). Disability studies scholar Shahd Alshammari, writing of her own experience with MS, attests to the power of images like this to show something about a condition that is difficult 'to capture, tame or hold down'. This is not just about recording physical symptoms, but the disturbance to someone's sense of self. As Alshammari continues: 
Typical of MS, this is not my body, these are not my hands or my feet, and my mind has broken up from my body. The mirror, the tool that identifies me as 'me', that confirms my existence, has failed to reflect my body. As an MS patient, when I look into the mirror in the morning I am searching for fragments of myself. I am also checking for any sudden physical changes, abnormalities. (email correspondence with author, 16 June 2016)

Mirrors are central to Awakenings and appear also in Laycock's previous projects. In Reconstructing Reality, she alludes to notions of folklore according to which the mirror is 'a form of trickery or optical allusion in which one reality shifts into another reality'. For example, the mirror reflecting the sky in the photograph discussed before creates the impression of a portal opening up in the brick wall. As Laycock states:

There is often the desire to look at our own reflection in a mirror in the hope that we see what we hope and desire for ... Sometimes we may hope and desire so much to the extent that these profound wishes reflect outside ourselves and therefore glimpse, momentarily at what we wish for, which could be the wish to see a person again. ${ }^{21}$

In light of her later work dealing with MS, this desire could be reformulated as a wish to escape into a different reality (the mirror as a portal to another world) and to see a healthy or unified body; perhaps, the person she used to be before illness. The 'mirror stage', an important component in Jacques Lacan's reinterpretation of Freud, has shown how the external image of the body (reflected in a mirror, or embodied for the infant through the mother) produces a psychic response that gives rise to the mental representation of an 'I'. According to his model, this sense of self relies on a 'misrecognition', for I am never fully 'myself' because the relationship within which my ego, my ' $\mathrm{I}$ ', comes into being is a relationship with an image that is not $m e$, that is an unattainable ideal. The mirror stage is an ongoing stage of human psychological development that shapes the relationship between the 'I' and its image of itself beyond childhood. $^{22}$ Another photograph from Awakenings, where Laycock's face is reflected in a small round mirror that hangs from a bright wall, equally suggests a longing for such 'an unattainable ideal' for a unified body/self that becomes even more removed through illness (figure 7). When the perspective of the viewer rather than the subject mirrored is considered, unlike the series Primacy Subject, this image does not obstruct or frustrate the observer. We clearly see the artist's face, eyes open for the first time, but once again disconnected from the body, as the mirror is not a full body one: to recall Alshammari's words, 'the mirror, the tool that identifies me as "me," that confirms my existence, has failed to reflect my body'. What is interesting about this photograph, moreover, is that viewers only see the reflection of the face in the mirror rather than the subject's actual (although photographed) face. The portrait, in other words, emphasises fragmentation by removing the artist from the ideal of a unified body and by creating more distance between the artist's body and her audience.

Considering the common belief that mirrors reflect the inner self', the focus of this image on the face can be also viewed as a way of negotiating the relationship between mind (or the inner self') and the body that many patients with MS describe as fraught: "I felt and still do ...that this "thing" which was taking over my body had nothing to do with "me" inside it. I am trapped inside somewhere struggling to survive' (p. 42 in Robinson ${ }^{23}$ ). This statement by a person with MS is indicative of the kind of disassociation from the body that occurs as the condition progresses, and also interrogates the extent to which it is

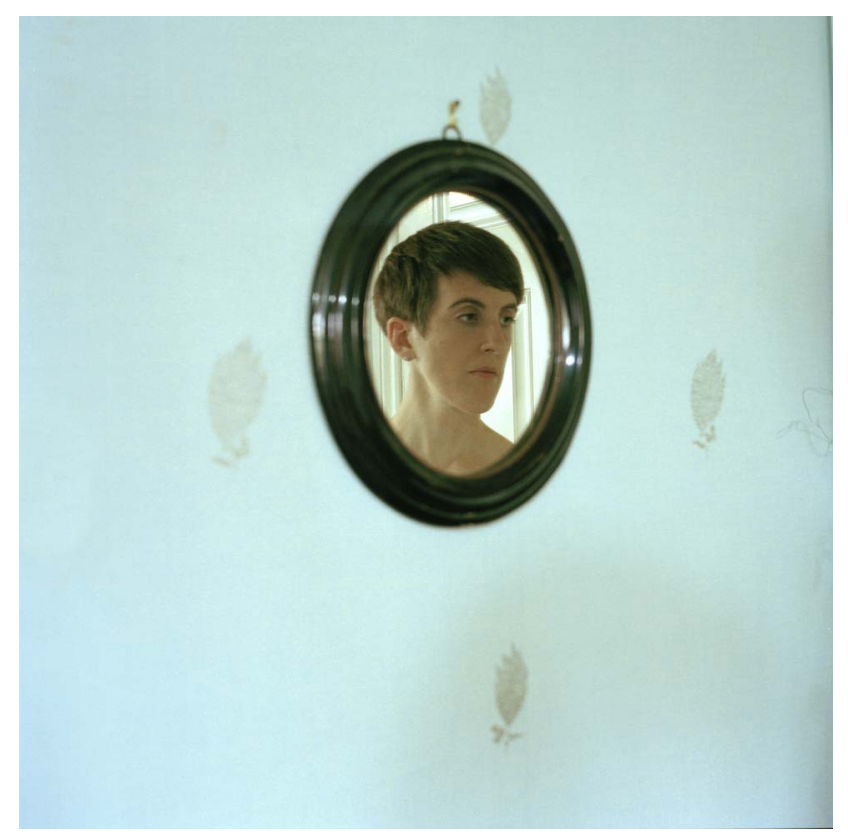

Figure 7 Hannah Laycock, Untitled, Awakenings, July 2015, Scotland.

possible to separate the self from the body. Even though the body appears as if it has a life or will of its own when it turns against itself or has to be subjected to various medical and other regulatory regimes, the chronically ill individual paradoxically needs it in order to continue to survive and experience the world. As Laycock has drawn on the rich mythology surrounding mirrors in earlier work, the belief that one's soul could become trapped in the mirror acquires a new poignancy in her MS projects: the image of the artist's face in the mirror evokes the kind of entrapment that is felt by people who experience a breakdown between their body and mind/soul that in turn calls their sense of self into question. At the same time, the 'magical' power of this mirror/image, unlike that of mirrors in many legends and tales, is that it reveals another kind of reality and truth-about living with chronic illness-by fashioning 'a world of illness' (p. 188 in Radley $^{7}$ ) and inviting its viewers to bear witness.

Unlike mirrors and their mythology, skin is not considered to reflect the interior of the self. It is important, nevertheless, as 'a boundary-object' connecting, as it does, the inside and the outside (p. 2 in Ahmed and Stacey ${ }^{24}$ ). Moreover, illness often leaves its marks on the skin which can communicate (like a language) a range of experiences through scars, self-harm or wounds. In her project, Fragility, Laycock has acknowledged the skin as a site of exposure:

Solid as we may appear on the outside the simple fact is our fragility begins with the skin, an element that can appear as delicate as paper ... Skin is our make-up, and as long as our skin is seen as a whole, and not torn or wounded, then it hides us from the bear reality of what lies beneath this protective layer, we will in certain circumstances continue to mistreat or use our bodies as a war-zone. ${ }^{25}$

Three performative images from Awakenings reframe the concept of fragility through the experience of MS. In these psychedelic self-portraits, the artist lies in a bathtub with colourful paint on her face and body gradually dissolving, so that the skin seems to melt or evaporate before our eyes (figure 8). In the third photograph (figure 9), her torso is no longer visible as it is 
submerged in a bright red-coloured background, but the face, eyes closed, looks tranquil. Even though these images allude to the body as war zone by using red paint, they are strikingly soothing. They recall Francis Bacon's paintings of blurred and distorted human heads and Jo Spence's Final Project after she had been diagnosed with leukaemia: in one of Spence's layered images, wearing only a black swimsuit, she lies against an oceanblue background overlaid with a scene from an operation table. Closer to Laycock's decaying portraits, in her Final Project, Spence reframed some of her earlier breast cancer photographs using effects (such as a peeling wall) that marked her ailing body with symbolic ruin. ${ }^{26}$

Laycock's series of disintegrating bodies could be seen as representing once again characteristics that are typical of MS, but in an experiential or lived way. One patient with MS admits to feeling that 'her body dies a bit more each time' (p. 42 in Robinson ${ }^{23}$ ), and the decomposition of the face and body in these pictures captures that perception very vividly. The body attacking itself, which is what characterises an immune-mediated disease, is difficult to conceptualise by many patients, and medical interpretations are often deemed inadequate; Laycock's series shows this process (there is nothing external that is attacking the body in her image) in a way that prioritises sensations and feelings rather than biomedical data or statistics. Artistic work such as Laycock's can therefore complement medical images and reduce anxiety; it can help patients relate to their ill bodies better by giving them the opportunity to interpret them together with their doctors.

But, in the context of some of the other photographs in Awakenings that convey a sense of escape from bodily constraints, an additional reading emerges. Laycock mentions that she once read of 'a mother that had just been told her son had taken his own life, and how that was the first time in 15 years that she wasn't aware of her condition, the first time she forgot about its suffocating presence'. As she continues, 'in July 2015 I looked for that same breakthrough. Not for the wrenching heartache for a loved one that had taken their own life, but for a single moment when I could forget my condition was there'. ${ }^{19}$ The single moment of release from bodily limitations-or of

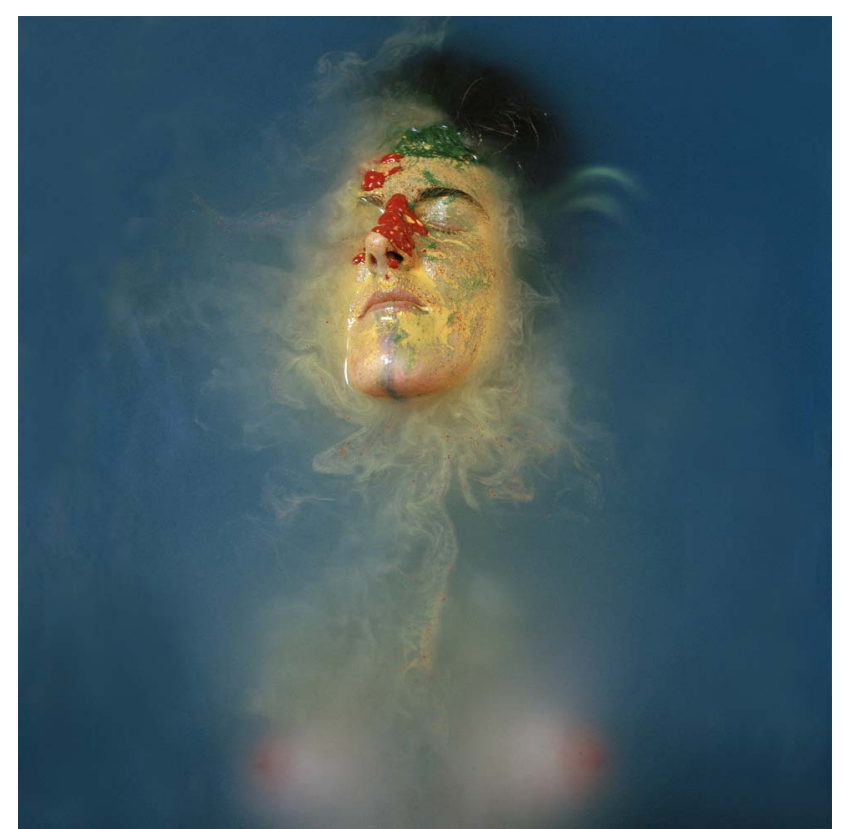

Figure 8 Hannah Laycock, Untitled, Awakenings, July 2015, Scotland.

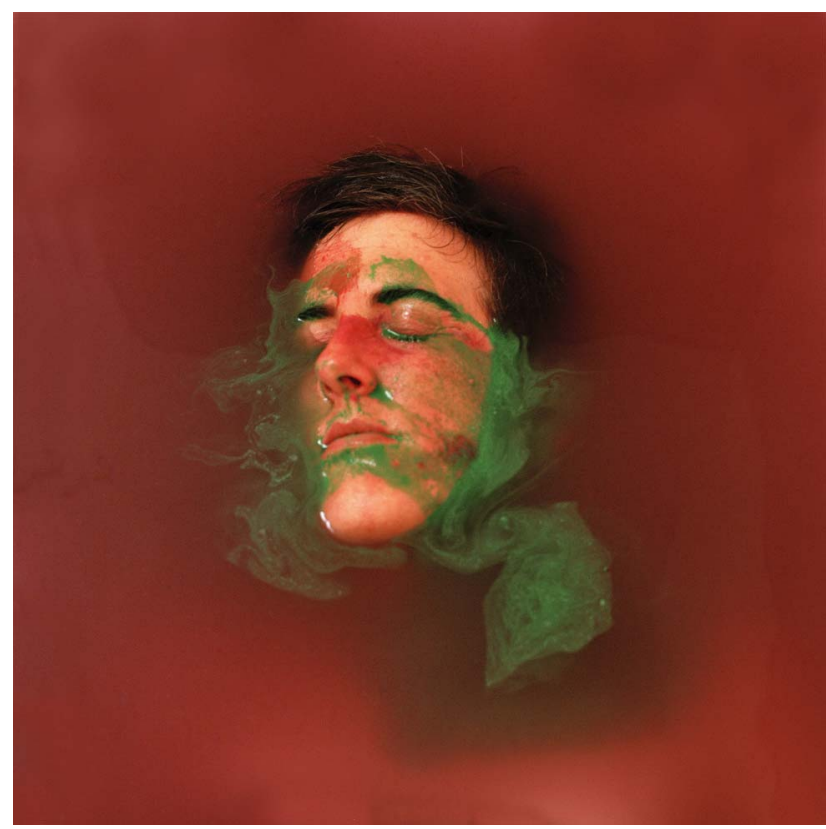

Figure 9 Hannah Laycock, Untitled, Awakenings, July 2015, Scotland.

forgetting - comes close to being experienced as drowning in these bath images, making the artist wonder whether this is what it takes to achieve liberation from a numb body (Skype interview with author, 22 May 2016).

\section{CONCLUDING REMARKS}

Sacks found that his patients' response to L-DOPA was mediated by their individual personalities and their sense of identity; as he stresses, it was not enough to 'animate patients chemically', but it was necessary for them to 'find or make a life with purpose and meaning'. Asserting the therapeutic power of art, he notes that 'inert, etymologically, is the privative of art ... And one of the cures for inertia is art'. ${ }^{27}$ The photographs discussed in this essay are an antidote to inertia; Laycock further confirms that when she states that turning to her camera was a way 'to break free from the numbness of living with Multiple Sclerosis'. She also adds in her statement for Awakenings a line from Thom Gunn's poem 'On the Move' which also gave Sacks, a friend of Gunn's, the title of his own memoir: 'One is always nearer by not keeping still' (ref. 19, emphasis added). Like Mairs who 'summons up' a new voice in her prose, found 'in the body-warmed breath escaping [her] lungs and throat' (pp 95-6 in Mairs ${ }^{4}$ ), Laycock's embodied photography animates her body, calls it to wake up, forces an awakening. ${ }^{\text {iv }}$

Citing EM Forster, Sacks explains that art has a therapeutic power as strong as drugs but does not function in the same way; the 'creative impulse' has to be released before it can gradually start to act, just as it is perhaps suggested in Laycock's images (from Awakenings) of a body that effervesces, adding colour to

${ }^{i v}$ It is worth drawing a parallel here between fighting inertia and 'MS energy', the term used by the Shift.ms charity to describe a positive shift in outlook when coping with serious illness, or 'finding the good out of bad situations'. 'MS energy' is not only open to writers and artists as the MS energy stories that take various shapes and forms on the charity's website demonstrate. Like the dual meaning of awakening, MS energy goes beyond the idea of physical 'alertness' and stands for 'unlocking one's potential' in ways that are unique to each individual with this condition (MS energy, https://shift.ms/what-is-ms-energy (accessed 30 July 2016).) 
bathwater in order to counteract its haziness in one of her previous photographs from Perceiving Identity. Unlike drugs which work in 'some partial and mechanical way', art-and we could add narrative or other ways of animating lives and stories - 'evokes a self' and a world. ${ }^{27}$

As much as it is important for patients to rebuild the worlds that have been changed by illness (to echo Sacks), it is equally important for the healthcare community to enter into patients' experiences and worlds. Writing about the 'Good out of Bad' exhibition $^{\mathrm{v}}$ that featured Laycock's photography together with the works by fellow artists with MS, Bryony Birkbeck and Kirsty Stevens, Julia Pakpoor, a BMJ Clegg scholar and final year medical student at the University of Oxford, notes: 'Whilst beneficial for the MSers who used the art to reflect on their diagnosis, it is a shame that these types of patient engagement events are not more widely attended by clinicians'. ${ }^{28}$ This could be attributed to the fact that work like Laycock's may be perceived as not relevant because it does not focus explicitly on medical content or as difficult due to its artistic complexity. However, as this analysis has shown, it is precisely because it offers alternative ways of visualising the body that resist singular interpretation and can empower patients that non-medical photography needs to inform clinical practice. ${ }^{\mathrm{vi}}$ As Pakpoor continues, 'MSers all have different fears, different dreams, and different approaches to their illness. A targeted conversation between clinicians and patients would help mutual understanding. ${ }^{28}$ In communicating aspects of an 'invisible' and often misunderstood condition through their evocative qualities, Perceiving Identity and Awakenings are a powerful addition to a body of artistic and medical humanities work that captures the physical, social and emotional worlds of chronic illness.

Acknowledgements Small portions of this essay have been published in the Scottish Society for the History of Photography's journal Studies in Photography (http://sshop.org.uk/articles/). The author is grateful to the chief editor Dr Katherine Parhar for giving permission to reprint them here and for facilitating contact with Hannah Laycock. The author also acknowledges Laycock's help and permission to reproduce images from Perceiving Identity and Awakenings for this essay. Finally, the author thanks Dr Shahd Alshammari for her comments on Laycock's work and for allowing to citing personal correspondence.

\footnotetext{
${ }^{\text {v} S h i f t . m s ~ p r e s e n t ~ \# G O O B: ~ t h e ~ p r i v a t e ~ v i e w . ~ Y o u T u b e ~ v i d e o, ~ h t t p s: / / m . ~}$ youtube.com/watch?v=Gv4_xj8dw2s (accessed 30 July 216).

${ }^{\mathrm{vi}}$ Also see a collaborative project between a patient with MS and a printmaker involving the incorporation of medical images into fine art. $^{29}$
}

Competing interests None declared.

Provenance and peer review Not commissioned; externally peer reviewed.

\section{REFERENCES}

1 Laycock H. Artist's statement. http://www.hannahlaycock.com/Portfolio/ Railing-At-The-Enthrallment-To-The-Failing-of-The-.aspx (accessed 30 Jul 2016).

2 Bolaki S. Illness as many narratives: arts, medicine and culture. Edinburgh: Edinburgh University Press, 2016.

3 Whelan D. The artists explaining their multiple sclerosis through art. Vice, 23 November 2015. http://www.vice.com/en_uk/read/a-hidden-disese-understandingmultiple-sclerosis-through-art-225 (accessed 30 Jul 2016).

4 Mairs N. Carnal acts: essays. Boston: Beacon Press, 1996.

5 Padfield D, Hurwitz B, eds. Perceptions of pain. Stockport: Dewi Lewis Publising, 2003.

6 Spence J. Cultural sniping: the art of transgression. London: Routledge, 1995

7 Radley A. Works of illness: narrative, picturing, and the social response to serious disease. Ashby-de-la-Zouch: InkerMen Press, 2009.

8 Sontag S. Regarding the pain of others. London: Penguin, 2004.

9 Burgin V, ed. Thinking photography. London: Macmillan, 1982.

10 Laycock H. Artist's statement. http://www.hannahlaycock.com/Portfolio/PerceivingIdentity.aspx (accessed 30 July 2016).

11 Carel H. Illness: the cry of the flesh. Stocksfield: Acumen, 2008.

12 Svenaeus F. What is phenomenology of medicine? embodiment, illness and beingin-the-world. In: Carel H, Cooper R, eds. Health, illness and disease: philosophical essays. Durham: Acumen, 2012:97-111.

13 Laycock H. Artist's statement. http://www.hannahlaycock.com/Portfolio/Portraitureand-The-Gaze.aspx (accessed 30 Jul 2016).

14 Foucault M. The birth of the clinic: an archaeology of medical perception, trans. A. M. Sheridan. Abingdon: Routledge, 1989.

15 Kuppers P. The scar of visibility: medical performances and contemporary art. Minneapolis: University of Minnesota Press, 2007.

16 Toombs SK. Illness and the paradigm of lived body. Theor Med 1988;9:201-26.

17 Sacks O. Clinical tales. Lit Med 1986;5:16-23.

18 Sacks O. Awakenings. London: Picador, 2012.

19 Laycock H. Artist's statement. http://www. hannahlaycock.com/Portfolio/Awakenings. aspx (accessed 30 Jul 2016).

20 Sontag S. Illness as metaphor and AIDS and its metaphors. London: Penguin, 1991.

21 Laycock H. Artist's statement. http://www.hannahlaycock.com/Portfolio/ Reconstructing-Reality.aspx (accessed $30 \mathrm{Jul}$ 2016).

22 Lacan J. The mirror stage as formative of the function of the I as revealed in psychoanalytic experience. In: Fink B, trans. Écrits: the first complete edition in English. New York: Norton, 2007:75-81.

23 Robinson I. Multiple sclerosis. London: Routledge, 1988.

24 Ahmed S, Stacey J. Introduction: dermographies. In: Ahmed S, Stacey J, eds. Thinking through the skin. London: Routledge, 2001:1-17.

25 Laycock H. Artist's statement. http://www.hannahlaycock.com/Portfolio/Fragility.aspx (accessed 30 Jul 2016).

26 Lee L, ed. Jo Spence: the final project. Manchester: Riding House, 2013.

27 Sacks O. Neurology and the soul. New York Rev Books, 22 November 1990. http:/l www.nybooks.com/articles/1990/11/22/neurology-and-the-soul/ (accessed 30 Jul 2016).

28 Pakpoor J. Three artists with multiple sclerosis respond to 'good out of bad'. BMJ 2015. https://blogs.bmj.com/bmj/2015/03/12/julia-pakpoor-three-artists-withmultiple-sclerosis-respond-to-good-out-of-bad/ (accessed 30 Jul 2016).

29 Stahl D, Stahl DG. Seeing illness in art and medicine: a patient and printmaker collaboration. Med Humanit 2016;42:155-9. 